\title{
A Predictive Control Strategy for Mitigation of Commutation Failure in LCC-Based HVDC Systems
}

Sohrab Mirsaeidi, Member, IEEE, Xinzhou Dong, Fellow, IEEE, Dimitrios Tzelepis, Member, IEEE, Dalila Mat Said, Member, IEEE, Adam Dyśko, Member, IEEE, and Campbell Booth

\begin{abstract}
High-Voltage Direct Current (HVDC) systems are being widely employed in various applications because of their numerous advantages such as bulk power transmission, efficient long-distance transmission, and flexible power-flow control. However, Line-Commutated Converter (LCC) based HVDC systems suffer from commutation failure which is a major drawback, leading to increased device stress and interruptions in transmitted power. This paper proposes a predictive control strategy, deploying a Commutation Failure Prevention Module (CFPM) to mitigate the commutation failures during AC system faults. The salient feature of the proposed strategy is that it has the ability to temporarily decrease the firing angle of thyristor valves depending on the fault intensity to ensure a sufficient commutation margin. In order to validate the performance of the proposed strategy several simulations have been conducted on CIGRE Benchmark HVDC model using PSCAD/EMTDC software. Additionally, practical performance and feasibility of the proposed strategy is evaluated through laboratory testing, using the real time Opal-RT hardware prototyping platform. Simulation and experimental results demonstrate that the proposed strategy can effectively inhibit the commutation failure or repetitive commutation failures under different fault types, fault impedances and fault initiation times.
\end{abstract}

Keywords: HVDC transmission, line-commutated converters, commutation failure, AC faults, predictive control strategy.

\section{Introduction}

HVDC transmission based on LCC technology has been extensively used throughout the world for power transmission, either as long-distance interconnections or back-to-back asynchronous links $[1,2,3]$. Even though the Voltage-Source Converter (VSC) based HVDC system is a much more modern technology which can be the most suitable option for Multi-Terminal Direct Current (MTDC) grids, the conventional thyristor-based LCC technology is still superior to self-commutating VSC transmission in terms of power losses, capital cost, stability and reliability for large-scale HVDC networks [4].

In spite of the large number of studies in the field of LCC-based HVDC systems, some of their common drawbacks are still exist which need to be resolved by power system engineers and researchers. Commutation failure is one of

\footnotetext{
${ }^{2}$ S. Mirsaeidi and X. Dong are with the Department of Electrical Engineering, Tsinghua University, Beijing, People's Republic of China. (e-mail: m_sohrab@mail.tsinghua.edu.cn; xzdong@mail.tsinghua.edu.cn).

D. Tzelepis, A. Dyśko, and C. Booth are with the Department of Electronic \& Electrical Engineering, Strathclyde University, Glasgow, United Kingdom. (e-mail: dimitrios.tzelepis@strath.ac.uk; a.dysko@strath.ac.uk; campbell.d.booth@strath.ac.uk).

D. Mat Said is with the Centre of Electrical Energy Systems, Faculty of Electrical Engineering, Universiti Teknologi Malaysia, Johor, Malaysia. (corresponding author: e-mail: dalila@fke.utm.my).
} 
them which may occur as a consequence of voltage reduction due to $\mathrm{AC}$ system faults or switching actions close to the inverter station [5]. It may cause temporary outage of HVDC link, and hence influence the performance of whole power system. Moreover, commutation failure is always accompanied with a drastic current increase which leads to the overheat of thyristor valves, gradually shortening their lifespan [6].

Commutation failures are frequently occurring dynamic events which have been reported in many practical LCC-based HVDC projects around the world; for instance, National Power Grid of China recorded the concurrent commutation failures and forced blocking of converter stations in 2013. This accident caused a reduction of 4530 MW power transmitted by HVDC links, which led to a significant reduction of inverter side AC system frequency and an increase of power in the adjacent HVAC lines. Also the generators at rectifier side were tripped and spinning reserves were activated at inverter side to compensate for the loss of active power [7]. As a result, it is of significance to deeply study the mechanism of commutation failures and corrective measures to mitigate the above-mentioned consequences in the power systems.

To date, a number of alternative solutions have been proposed in the technical literature to reduce the risk of commutation failures in LCC-based HVDC systems through modification of control systems. The first solution is to maintain a constant margin angle control. However, it is identified in [8] that the constant margin angle control contrarily augments the voltage reduction, and thus leads to even more severe failures. Another solution is to enhance the margin angle control when a reduction at inverter AC bus is sensed. Based on this approach and mechanism analysis of commutation failures, various firing angle control strategies are presented. In [9], a technique is proposed to directly detect the deionization margin angle and to prevent the commutation failure in the inverter station. In the proposed method, the deionization margin angle is measured by anode-cathode voltage of the valve and AC phase voltage. Nevertheless, it is recognized in [10] that direct measurement of the anode-cathode voltage is not always practically nor economically feasible. Furthermore, since there are six (or twelve) valves in a converter, it is necessary to obtain the minimum value of the extinction angle of all the valves. Reference [11] presents a control strategy which reduces the firing angle of valves once the commutating voltage is distorted. In this approach, the commutating voltage distortion is detected by extraction of its harmonic components, but according to [12], the time required to extract the harmonic components of a signal depends on its fundamental frequency which takes $20 \mathrm{~ms}$ in a $50 \mathrm{~Hz}$ system. Therefore, the proposed approach can only be effective in preventing repetitive commutation failures. In [13], a control strategy is developed to reduce the risk of commutation failures caused by single line to ground faults. The idea is to continuously monitor the supply line voltage and to calculate whether a particular voltage change is so dangerous that it becomes necessary to advance the firing time for the thyristors. If this is the case, the control strategy is changed immediately. However, in this work, only commutation failures caused by single line to ground faults are taken into account. Also, a commutation failure prevention function is developed in [14] to immediately deduct an additional angle from the firing angle in case of a fault incident at the inverter $\mathrm{AC}$ side. In the developed function, zero-sequence component and $a b c-\alpha \beta$ transformation are applied to recognize unsymmetrical and symmetrical faults, respectively. Nevertheless, the intensity of the fault incident is neglected for determination of the reduced firing angle. In [15], an alternative technique is proposed based on reduction of commutated DC current by lowering the current order at rectifier side after detection of an $\mathrm{AC}$ voltage disturbance. Even though the proposed technique remedies the problems 
of other previous methods, the change of current order at rectifier side cannot be quick enough regarding the normally long distance of HVDC links.

Based on further investigation of commutation failure mechanism, this paper proposes a predictive control strategy, deploying a Commutation Failure Prevention Module (CFPM) to mitigate the commutation failures in LCC-based HVDC systems. In case of a fault incident on the inverter side, the developed CFPM temporarily decreases the firing angle of thyristor valves depending on the fault intensity to ensure a sufficient commutation margin.

The remainder of this paper is as follows: In Section 2, the commutation process in normal and fault conditions is discussed; Section 3 describes the proposed predictive control strategy for commutation failure mitigation; In Section 4 , the effectiveness of the proposed strategy is validated using several simulations on the CIGRE Benchmark HVDC model; Section 5 evaluates the practical performance and feasibility of the proposed strategy through laboratory testing; and finally, Section 6 concludes the paper.

\section{Commutation process in normal and fault conditions}

\subsection{Commutation process in normal conditions}

Graetz Bridge is the most universally used configuration for HVDC line-commutated converters. It includes six thyristor valves, each connecting one of the three phases to one of the two DC terminals. The Graetz bridge can be employed for power transmission in two directions by applying different firing angles to its thyristor valves. If the firing angle is set up to 90 degrees, the output DC voltage becomes positive and the bridge operates in the rectifier mode by flowing the power from the AC side to the DC side; instead, if the firing angle is made greater than 90 degrees, the DC voltage polarity changes and the converter acts as an inverter by reversing the direction of power flow $[16,17,18]$. Fig. 1(a) shows the configuration of the Graetz bridge in the inverter mode.

The switching of current conduction from one of the thyristor valves to another in the same row is referred to as commutation [19]. Due to the inductance of the supply lines and filters, and the leakage inductance of the converter transformer, commutation process cannot be instantaneous and takes for a certain time which is termed as overlap time or angle of overlap $(\mu)$. For successful switching a thyristor valve in an LCC, a certain time is required that its internal stored charge produced during a forward conduction interval of a valve be eliminated before it can establish a forward voltage blocking capability. This time is referred to as de-ionization time or angle of extinction $(\gamma)[20]$. Considering the case, where valves $T_{1}$ and $T_{2}$ are conducting, and the conduction of current is going to be switched from valve $T_{1}$ to valve $T_{3}$ in the bottom row of the Graetz bridge shown in Fig. 1(a). Once valve $T_{3}$ was fired, a reverse voltage $V_{b}-V_{a}$, referred to as commutating voltage, attempts to turn off the valve $T_{1}$. A successful commutation can take place as long as the voltage is positive, otherwise a commutation failure happens and power transmission is temporarily interrupted. The equivalent circuit of Graetz bridge during the commutation process between valves $T_{1}$ and $T_{3}$ in the inverter operation mode is shown in Fig. 1(b). As can be seen from the figure, a circulating current $(i)$, referred to as commutating current, flows in the opposite direction of $i_{T 1 i}$ during the commutation and tries to decrease it. 


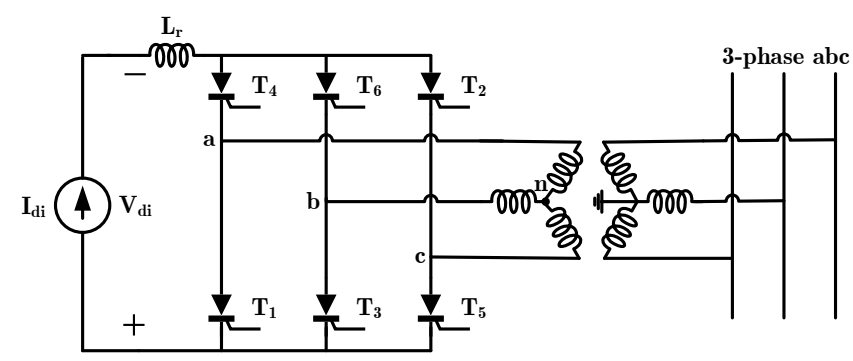

a)

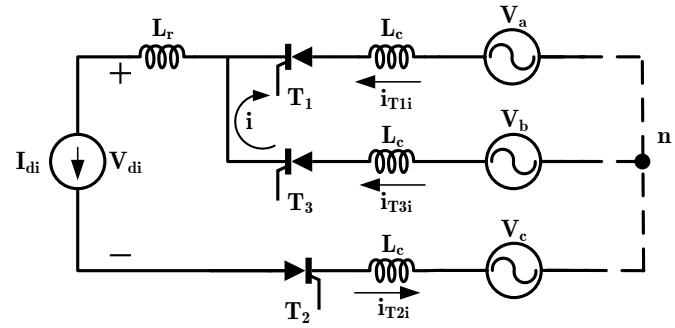

b)

Figure 1: (a) Graetz bridge in the inverter mode. (b) The equivalent circuit of Graetz bridge during the commutation process between valves $T_{1}$ and $T_{3}$ in the inverter mode.

This process lasts until $i_{T 1 i}$ becomes zero and the commutating current becomes equal to the direct current $I_{d i}$. This is demonstrated in Fig. 2, where $\alpha_{i}, i_{T 1 i}$ and $i_{T 3 i}$ are respectively, firing angle of valve $T_{3}$ and the currents flowing through valves $T_{1}$ and $T_{3}$ in the inverter operation mode.

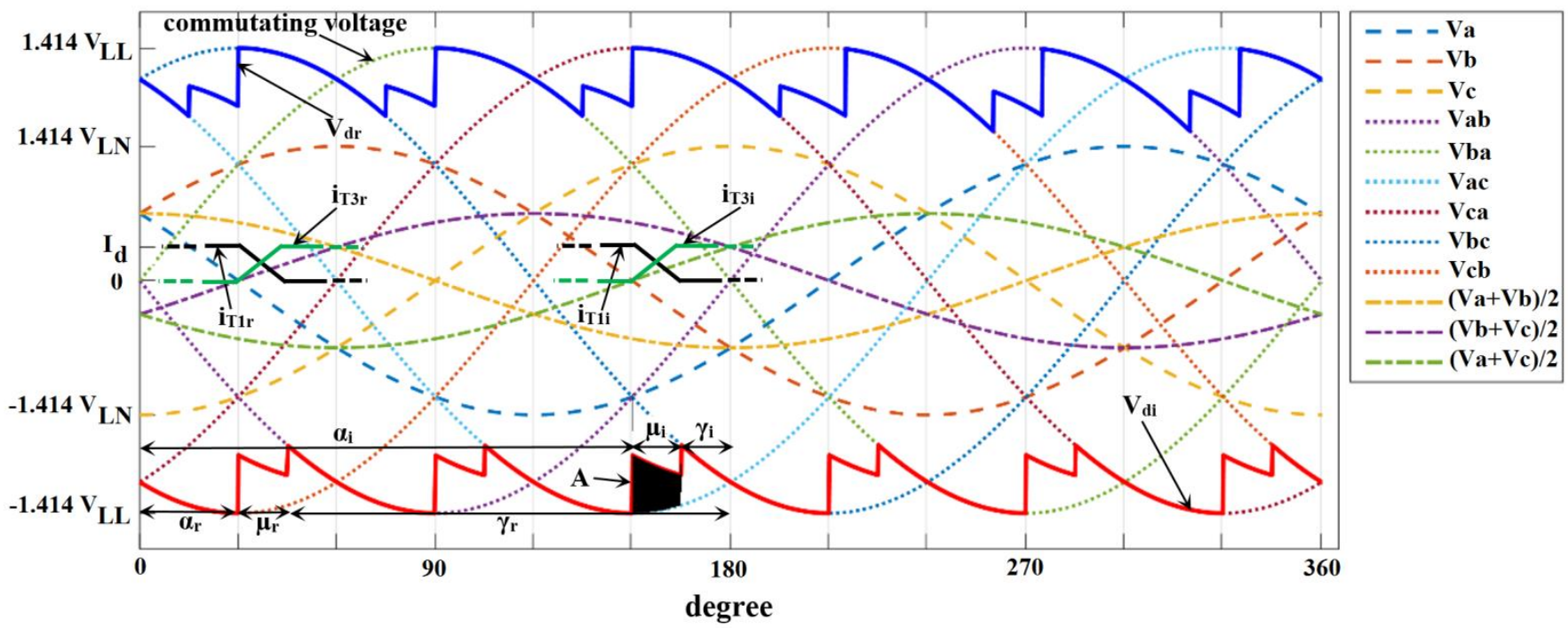

Figure 2: DC voltage and direct current waveforms of the Graetz bridge during rectifier and inverter modes.

It can be also seen from Fig. 2 that the DC voltage in the inverter mode $\left(V_{d i}\right)$ during the commutation process is reduced due to the effect of overlap. The average DC voltage in the this mode can be calculated by:

$$
V_{d i}=-\frac{3 \sqrt{6}}{\pi} V_{L N} \cos \alpha_{i}+\Delta V_{\text {com. }}=\frac{3 \sqrt{6} V_{L N}}{2 \pi}\left(\cos \gamma_{i}-\cos \alpha_{i}\right)
$$

In this equation, $V_{L N}$ is the rms line-to-neutral $\mathrm{AC}$ voltage, and $\Delta V_{\text {com. }}$. denotes the average of $\mathrm{DC}$ voltage drop 
during comutation which can be expressed as:

$$
\Delta V_{\text {com. }}=\frac{3}{\pi} A=R_{c} I_{d i}
$$

Where, $R_{c}=\frac{3}{\pi} \omega L_{c}$ is the equivalent commutation resistance and $A$ and is the area resulting from voltage drop during the commutation which is shown in Fig.2. Also, $I_{d i}$ represents the direct current which can be calculated by:

$$
I_{d i}=\frac{\sqrt{6} V_{L N}}{2 \omega L_{c}}\left(\cos \gamma_{i}+\cos \alpha_{i}\right)
$$

The same analysis can also be performed for the rectifier operation mode except that valve $T_{3}$ is fired at $\alpha_{r}$. It can be seen from Fig. 2 that the remaining of commutating voltage in this mode $\left(\gamma_{r}\right)$ is large enough for a successful commutation, and hence commutation failures rarely happen in the rectifier mode.

\subsection{Commutation process in fault conditions}

As mentioned before, the risk of commutation failure in the inverter mode is much higher than that in the rectifier mode. Because of this, commutation failures in LCC-based HVDC systems often take place in the inverter stations due to the voltage disturbances resulting from the AC faults at their AC side [21]. AC faults can be of symmetrical three phase or non-symmetrical type.

Symmetrical three phase faults reduce the voltage magnitude of all three phases in a balanced manner, but do not result in distortion of phase angles. Assuming that the firing angle does not change during such fault, the overlap area increases proportional to the direct current, and hence the post-fault extinction angle decreases. Fig. 3(a) illustrates how a reduction in the commutating voltage influences the commutation process.

Non-symmetrical faults which are the most frequent type in the power systems lead to distortions of commutating voltage. Such types of faults not only reduce the commutating voltage magnitude, but also result in phase angle shifts. Phase angle shifts may be either backward or forward. However, only backward phase angle shifts have negative influence on the commutation process. The effect of a backward phase angle shift on the commutation process is shown in Fig. 3(b) which can be analyzed similar to Fig. 3(a).

\section{Proposed predictive control strategy}

\subsection{Design of LCC-based HVDC controllers}

Transmission of large amounts of electric power through HVDC systems can only be accomplished under tightly controlled conditions. HVDC control systems should have the ability to precisely affect DC voltage and current to provide the desired power transfer. Two-terminal HVDC system is the most used configuration which contains a rectifier and an inverter station, each of which has its own control system. The steady state $V_{d}-I_{d}$ control characteristic of an HVDC system is shown in Fig. 4. As can be seen from the figure, the control system at the rectifier station includes min- $\alpha$, Constant Current (CC) and min $-I_{d}$ controllers, and Voltage Dependent Current Order Limiter (VDCOL); and the inverter control system consists of $\min -\gamma$, current error and CC controllers, and VDCOL. 

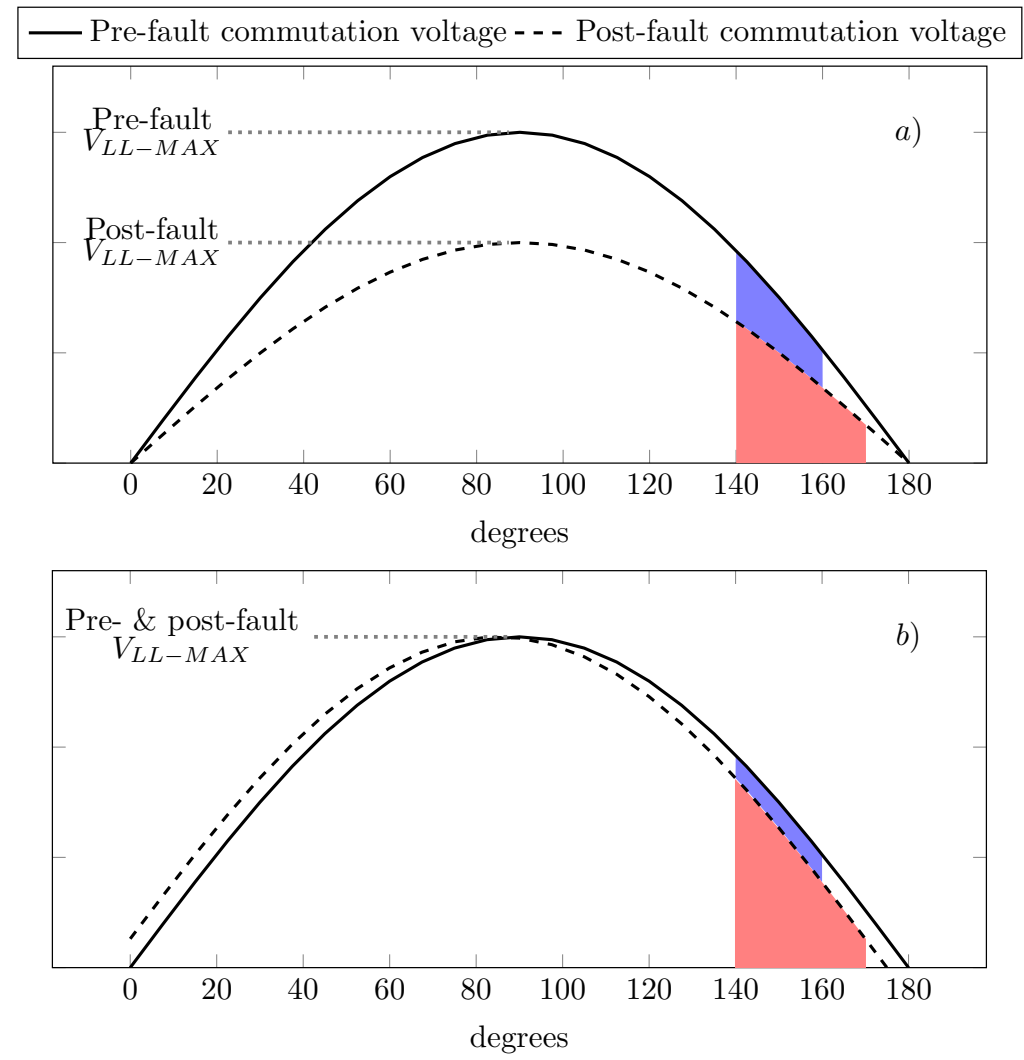

Figure 3: Reduction of commutation margin due to: (a) reduced commutating voltage magnitude, (b) backward phase angle shift of commutating voltage.

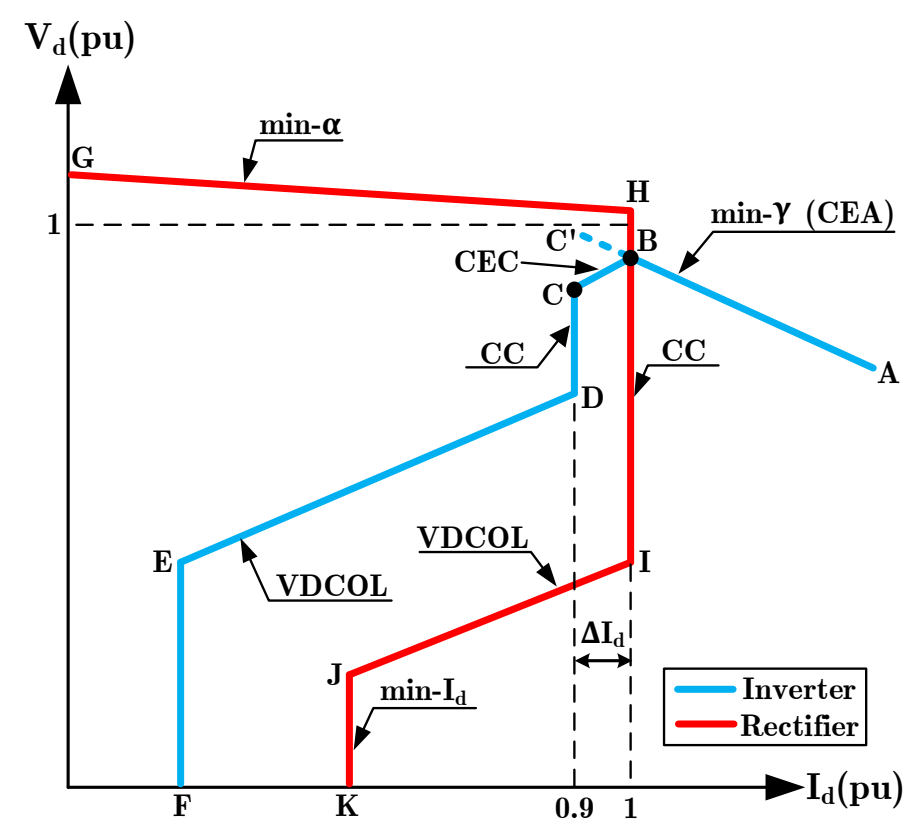

Figure 4: Steady state $V_{d}-I_{d}$ control characteristic of an HVDC system.

It should be noted that the rectifier and inverter stations must have controllers in operation that are opposite to each other. Otherwise, the operational intersection point between rectifier and inverter stations will not be created and 
the control system will never become stable [22].

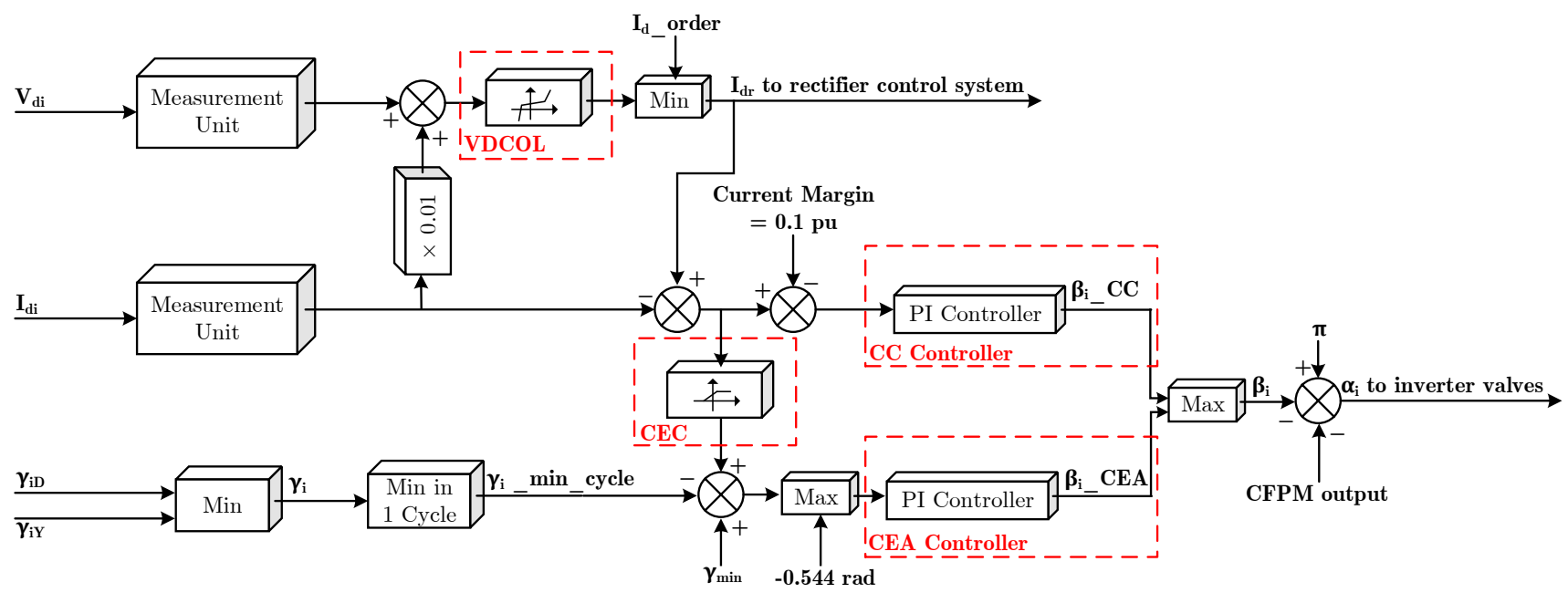

Figure 5: Block diagram of the inverter control system.

Fig. 5 depicts the block diagram of the inverter control system consisted of four controllers which are described in detail as follows:

(i) $\min -\gamma$ controller: Line $\mathrm{AB}$ in Fig. 4 shows the $V_{d}-I_{d}$ characteristic of this controller which is plotted according to Equation (3). min- $\gamma$ controller (also referred to as Constant Extinction Angle (CEA) controller) is used to regulate the DC voltage under normal conditions. This controller ensures the extinction angle remains at its minimum value ( $\gamma_{\min }$ in Fig. 5) to reduce the reactive power consumption of the inverter.

(ii) Constant Current (CC) controller: Line CD in Fig. 4 defines the constant current characteristic of operation at the inverter. In order to maintain a unique operating point of the DC link, defined by the intersection point B of the rectifier and inverter characteristics, a current margin of $\Delta I_{d}=I_{d r}-I_{d i}$ is considered. Even though the current demanded by the inverter $I_{d i}$ is usually less than the current demanded by the rectifier $I_{d r}$, the current margin is set to be large enough (typically $0.1 \mathrm{pu}$ as shown in Figs. 4 and 5) so that the rectifier and inverter constant current modes do not interact due to any current harmonics which may be superimposed on the DC current [10].

(iii) Current Error Controller (CEC): When the inverter operates in a weak AC system, the slope of the CEA characteristic (Line $\mathrm{AB}$ ) is quite steep and may cause multiple intersection points with the rectifier characteristics. To avoid this, a current error controller (see block CEC in Fig. 5) is used to modify Line $\mathrm{BC}^{\prime}$ of the CEA characteristic in Fig. 4. The advantage of this controller becomes evident when there is a voltage reduction at the rectifier $\mathrm{AC}$ bus forcing the Line $\mathrm{GH}$ to move downwards. The operating point then moves to point $\mathrm{C}$ and the inverter switches to $\mathrm{CC}$ control.

(iv) Voltage Dependent Current Order Limiter (VDCOL): The purpose of deploying VDCOL is to prevent power instabilities during and after faults in the AC network. It reduces the stress on the inverter valves by decreasing the DC current during commutation failures involving short-circuit across the DC bus. Moreover, immediately after the fault clearance, VDCOL gradually increases the DC current according to the its function, which contributes to the recovery of the inverter station after commutation failures. 
Since the risk of commutation failure at the inverter station is higher than the rectifier one, the inverter control system is also equipped with a Commutation Failure Prevention Module (CFPM). The function of CFPM is to predict the commutation failures resulting from $\mathrm{AC}$ fault incidents as well as other system disturbances which may lead to reduced commutation margins. More precisely, once a fault occurred, CFPM detects the possibility of commutation failure by measuring the $\mathrm{AC}$ system instantaneous values, and then deducts an additional angle from the inverter firing angle to enlarge the commutation margin, thereby reducing the probability of commutation failures.

\subsection{Proposed Commutation Failure Prevention Module (CFPM)}

As discussed in Section 1, one of the main drawbacks of the existing firing angle-based control strategies is that the intensity of fault incident is neglected for determination of the reduced firing angle. In order to overcome this challenge, this paper proposes a CFPM based on Thevenin's impedance through Phasor Measurement Unit (PMU) measurements at the inverter AC bus. Since the value of Thevenin's impedance seen from the inverter AC bus decreases when the fault severity increases, it can be a suitable parameter for determination of the fault severity and deduction of the firing angle.

According to Thevenin's theorem, Thevenin's equivalent impedance for any two-terminal of the network is the impedance seen from those terminals when the sources are set to zero. Fig. 6 depicts the Thevenin's equivalent impedance seen from terminals $\mathrm{AB}$ during a fault with the impedance of $Z_{F}$, where the upstream and downstream equivalent voltage sources are set to zero. In the figure, the upstream and downstream equivalent impedances are respectively denoted by $Z_{U}$ and $Z_{D}$, and $x$ is a parameter which represents the distance from the fault location to the terminals AB. The Thevenin's equivalent impedance seen from terminals AB is calculated by:

$$
Z_{t}=Z_{U} \|\left(x Z_{D}+\left(Z_{F} \|(1-x) Z_{D}\right)\right)
$$

It can be seen from Equation (4) that the value of $Z_{t}$ decreases when the fault severity increases [23, 24, 25].

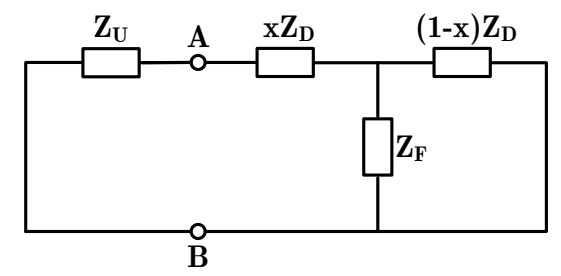

Figure 6: Thevenin's equivalent impedance seen from terminals AB during a fault with the impedance of $Z_{F}$.

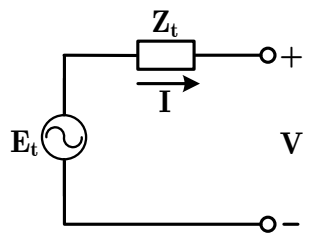

Figure 7: Thevenin's equivalent model. 
Based on Thevenin's equivalent model shown in Fig. 7, the voltage equation at each node of power system can be defined as:

$$
V=E_{t}-Z_{t} I
$$

According to (5), the voltage equation at inverter $\mathrm{AC}$ bus becomes:

$$
V_{i b}=E_{t i b}-Z_{t i b} I_{i b}
$$

Where, $E_{t i b}$ and $Z_{t i b}$ represent Thevenin's equivalent voltage source and Thevenin's equivalent impedance seen from the inverter AC bus station, respectively. The phasor diagrams of two $\left(V_{i b}, I_{i b}\right)$ pairs measured at different time instants by a PMU installed at inverter $\mathrm{AC}$ bus are displayed in Fig. 8. Since $E_{t i b}$ is the Thevenin's equivalent impedance seen from the inverter AC bus, its magnitude for both measurements are identical. However, its angle in the second measurement is shifted by an angle equal to the phase drift because of the variations in the system frequency.

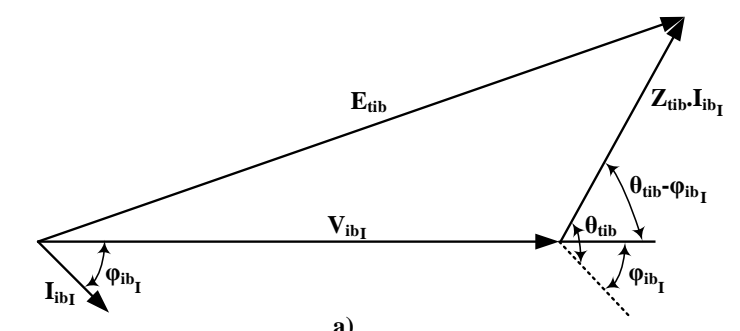

a)

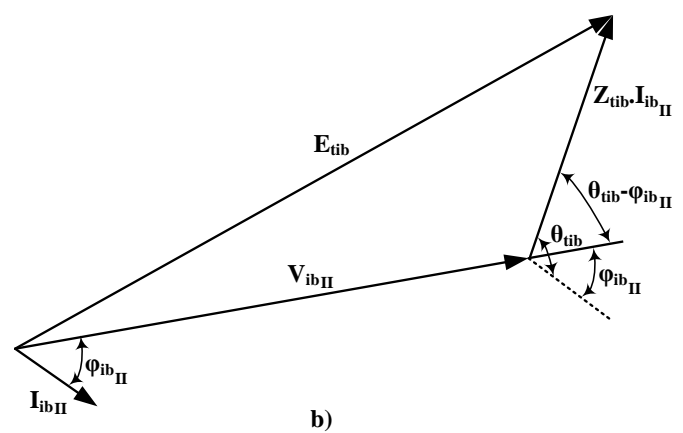

Figure 8: Phasor diagrams for two PMU measurements at different time instants at inverter AC bus: (a) First measurement, (b) Second measurement.

With reference to Fig. 8, equation of $E_{t i b}$ for the first measurement is expressed as follows:

$$
E_{t i b}^{2}=V_{i b_{I}}^{2}+I_{i b_{I}}^{2} Z_{t i b}^{2}+2 V_{i b_{I}} I_{i b_{I}} Z_{t i b} \cos \left(\theta_{t i b}-\phi_{i b_{I}}\right)
$$

By expanding $\cos \left(\theta_{t i b}-\phi_{i b_{I}}\right)=\cos \theta_{t i b} \cos \phi_{i b_{I}}+\sin \theta_{t i b} \sin \phi_{i b_{I}}$, and substituting $\cos \theta_{t i b}=\frac{R_{t i b}}{Z_{t i b}}, \sin \theta_{t i b}=\frac{X_{t i b}}{Z_{t i b}}$, $\cos \phi_{i b_{I}}=\frac{P_{i b_{I}}}{V_{i b_{I}} I_{i b_{I}}}$, and $\sin \phi_{i b_{I}}=\frac{Q_{i b_{I}}}{V_{i b_{I}} I_{i b_{I}}}$, Equation (7) can be written as:

$$
E_{t i b}^{2}=V_{t i b_{I}}^{2}+I_{i b_{I}}^{2} Z_{t i b}^{2}+2 P_{i b_{I}} R_{t i b}+2 Q_{i b_{I}} X_{t i b}
$$

Where, $R_{t i b}, X_{t i b}, P_{i b_{I}}, Q_{i b_{I}}$ represent Thevenin's equivalent resistance, Thevenin's equivalent reactance, active 
power and reactive power at inverter AC bus, respectively.

By following the same procedure, equation of $E_{t i b}$ for the second measurement can be expressed as:

$$
E_{t i b}^{2}=V_{t i b_{I I}}^{2}+I_{i b_{I I}}^{2} Z_{t i b}^{2}+2 P_{i b_{I I}} R_{t i b}+2 Q_{i b_{I I}} X_{t i b}
$$

By subtracting (9) from (8):

$$
V_{i b_{I}}^{2}-V_{i b_{I I}}^{2}+\left(I_{i b_{I}}^{2}-I_{i b_{I I}}^{2}\right) Z_{t i b}^{2}+2\left(P_{i b_{I}}-P_{i b_{I I}}\right) R_{t i b}+2\left(Q_{i b_{I}}-Q_{i b_{I I}}\right) X_{t i b}
$$

By substituting $Z_{t i b}=\sqrt{R_{t i b}^{2}+X_{t i b}^{2}}$ and arranging (10):

$$
\begin{gathered}
\left(R_{t i b}+\frac{P_{i b_{I}}-P_{i b_{I I}}}{I_{i b_{I}}^{2}-I_{i b_{I I}}^{2}}\right)^{2}+\left(X_{t i b}+\frac{Q_{i b_{I}}-Q_{i b_{I I}}}{I_{i b_{I}}^{2}-I_{i b_{I I}}^{2}}\right)^{2}= \\
\frac{V_{i b_{I I}}^{2}-V_{i b_{I}}^{2}}{I_{i b_{I}}^{2}-I_{i b_{I I}}^{2}}+\left(\frac{P_{i b_{I}}-P_{i b_{I I}}}{I_{i b_{I}}^{2}-I_{i b_{I I}}^{2}}\right)^{2}+\left(\frac{Q_{i b_{I}}-Q_{i b_{I I}}}{I_{i b_{I}}^{2}-I_{i b_{I I}}^{2}}\right)^{2}
\end{gathered}
$$

This is the equation of a circle with radius $r_{I, I I}=\sqrt{\frac{V_{i b_{I}}^{2}-V_{i b_{I}}^{2}}{I_{i b_{I}}^{2}-I_{i b_{I I}}^{2}}+\left(\frac{P_{i b_{I}}-P_{i b_{I I}}}{I_{i b_{I}}^{2}-I_{i b_{I I}}^{2}}\right)^{2}+\left(\frac{Q_{i b_{I}}-Q_{i b_{I I}}}{I_{i b_{I}}^{2}-I_{i b_{I I}}^{2}}\right)^{2}}$ centered at $O_{I, I I}=\left(\frac{P_{i b_{I}}-P_{i b_{I}}}{I_{i b_{I}}^{2}-I_{i b_{I I}}^{2}}, \frac{Q_{i b_{I I}}-Q_{i b_{I}}}{I_{i b_{I}}^{2}-I_{i b_{I I}}^{2}}\right)$ in the impedance plane which specifies a locus for Thevenin's impedance seen from the inverter $\mathrm{AC}$ bus. However, Equation (11) which is obtained by two $\left(V_{i b}, I_{i b}\right)$ pairs measured at different time instants cannot determine a certain value for $Z_{t i b}$. Hence, another measurement is required to be used with the first and second measurements to create two other circles for $Z_{t i b}$. The intersection of these three circles specifies a certain value for $Z_{t i b}$. It should be highlighted that since location, type and impedance of fault, and configuration of the connected AC network have influence on the values of voltage and current measured at the inverter AC bus, the impact of these factors are inherently taken into account in the obtained value of $Z_{t i b}$.

Assuming no losses in the inverter, the DC power fed into the inverter is equal to the AC power emanating from it:

$$
V_{d i} I_{d i}=3 V_{i b} I_{i b} \cos \phi_{i b}
$$

Substituting $V_{d i}, I_{d i}$ and $I_{i b}$ respectively from (1), (3) and (6) into (12), $\gamma_{i}$ can be expressed by:

$$
\gamma_{i}=\arccos \left(\sqrt{\frac{2 \pi \omega L_{c}\left(E_{t i b}-V_{i b}\right) \cos \phi_{i b}}{3 V_{i b} Z_{t i b}}+\cos ^{2} \alpha_{i}}\right)
$$

Assuming that the firing angle has not changed before CFPM activation, the required $\Delta \alpha$ which should be deducted 
from the valves' firing angle order to prevent the commutation failure can be calculated by:

$$
\Delta \alpha=\gamma_{\text {min }}-\underbrace{\arccos \left(\sqrt{\frac{2 \pi \omega L_{c}\left(E_{t i b}-V_{i b}\right) \cos \phi_{i b}}{3 V_{i b} Z_{t i b}}+\cos ^{2} \alpha_{i}}\right)}_{\gamma_{i}}
$$

where, $\gamma_{\min }$ is the minimum extinction angle in which commutation failure does not occur, and $\gamma_{i}$ is the reduced extinction angle due to the $\mathrm{AC}$ fault. Equation (14) shows that decrease of $Z_{t i b}$ increases $\Delta \alpha$. Moreover, it can be seen from Equation (4) that increase of fault intensity leads to reduction of the Thevenin's impedance. Therefore, more severe faults require larger $\Delta \alpha$. However, it was observed in both simulation and experimental results that values of $\Delta \alpha$ larger than $0.476 \mathrm{rad}$ contrarily cause more commutation failures. This can be also proved theoretically by Equation (1), in which reducing the firing angle leads to more reduction in the DC voltage and increases the risk of commutation failure. Therefore, Equation (14) was replaced by a look-up table, where the suitable $\Delta \alpha$ (between 0 to $0.476 \mathrm{rad}$ ) is selected through comparing between pre- and post-fault values of $Z_{t i b}$. Moreover, deployment of look-up table can significantly reduce the CFPM execution time, since retrieving a value from memory is much faster than undergoing a complicated computation.

The schematic diagram of the proposed CFPM is shown in Fig. 9. Once a fault occurs in the inverter AC side, the Thevenin's impedance seen from the inverter bus is compared with that before the fault by a comparator. Since only AC faults with voltage reduction of greater than $8 \%$ cause commutation failure [19], a pre-determined threshold value is required to avoid unnecessary decrease of firing angle which leads to increase of the converter reactive power consumption. If the difference between these values exceeded the threshold value, a trigger signal is sent to a positive edge-triggered monostable multivibrator. This multivibrator generates a single output pulse with duration of $\mathrm{T}$, when it sensed a positive edge on its input. The multivibrator output is connected to a multiplexer to select a $\Delta \alpha$ based on comparison between pre- and post- fault values of $Z_{t i b}$ during the period of $\mathrm{T}$ to decrease the risk of commutation failure. It should be noted that the proposed CFPM is executed in a $70 \mu \mathrm{s}$ step, which corresponds to 1.26 degrees in a $50 \mathrm{~Hz}$ system, by considering the highest level of the DSP controller and using a PMU with sampling rate of 512 samples per cycle. This ensures that the proposed CFPM has a fast reaction to change in Thevenin's impedance seen from the inverter AC bus. It should be also highlighted that the precision of the developed CFPM can be enhanced by increasing the number of $\left(V_{i b}, I_{i b}\right)$ pairs measured at different time instants by the PMU, but it necessitates reducing the CFPM execution time to less than or equal to $70 \mu \mathrm{s}$.

From the cost-effectiveness viewpoint, even though the main cost of the proposed control strategy is related to PMU, wide use of PMUs has resulted to relatively low cost of these devices. In fact, these devices have already been installed on numerous points on transmission and distribution levels on power networks. As such, by utilizing these devices and adding a few functions to the existing control systems of LCCs, the proposed solution can be very cost-effective. Moreover, in order to estimate the cost-effectiveness ratio of the proposed strategy, the serious consequences resulting from the commutation failures should be also taken into consideration. The significance of this issue becomes more evident when the inverter supplies several AC networks, where a fault incident on one of them may cause a commutation failure and influences the performance of all of the connected AC networks. 


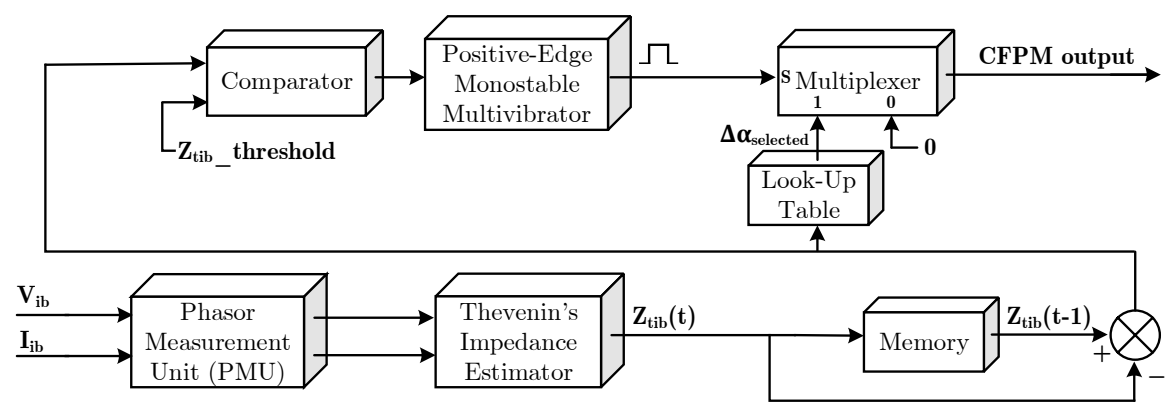

Figure 9: Schematic diagram of the proposed CFPM.

\section{Test network and case studies}

\subsection{Test network}

In order to validate the effectiveness of the proposed control strategy in this paper, several simulations have been performed using PSCAD/EMTDC software. The single line diagram of CIGRE Benchmark HVDC model which is used as test network is depicted in Fig. 10 [26]. As can be seen from the figure, the backbone of the test network is a mono-polar $500 \mathrm{kV}$ and 1000 MW HVDC link with 12-pulse converters on both rectifier and inverter sides. Smoothing reactors, AC filters, and shunt capacitors are also provided on both sides, and the filters are tuned to absorb the harmonics generated by the converters. The AC networks of converter stations are modelled by a voltage source in series with an impedance, and are connected to the transformers through rectifier and inverter buses (rb and ib in Fig. 10). The parameters of the test network are listed in Table 1.

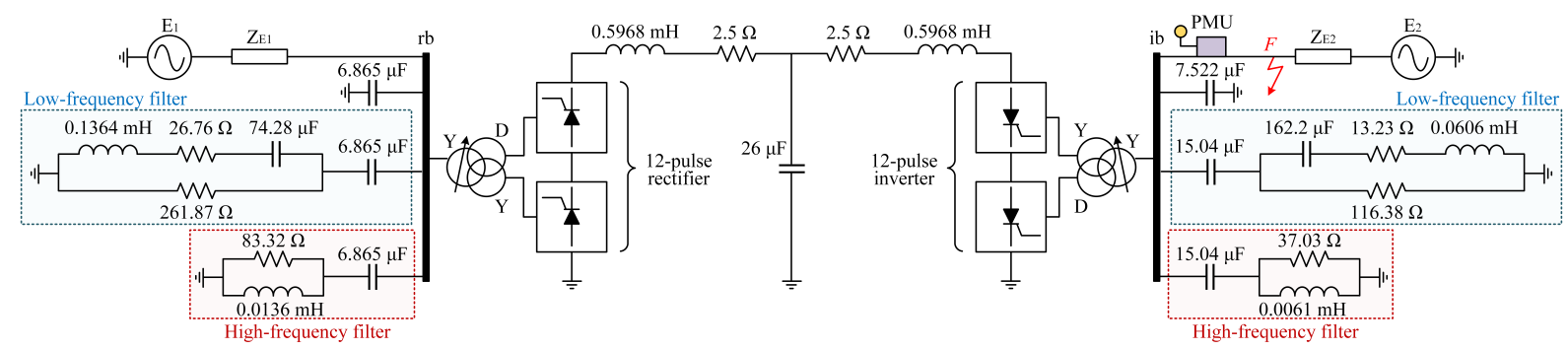

Figure 10: Single line diagram of the test network.

Table 1: Parameters of the test network

\begin{tabular}{c|c|c}
\hline \hline Parameter & Rectifier & Inverter \\
\hline AC system frequency $[\mathrm{Hz}]$ & 50 & 50 \\
Nominal firing angle [deg] & 15 & - \\
Minimum firing angle [deg] & 5 & 110 \\
Turn-off time of thyristor $[\mu \mathrm{s}]$ & 30 & 30 \\
\hline \hline
\end{tabular}

\subsection{Case studies}

Fig. 11 shows the performance of the proposed control strategy during different types of AC system faults at point F in Fig. 10. In all cases, fault is applied at $t=0.4 \mathrm{~s}$ for a duration of $0.4 \mathrm{~s}$, and the fault impedance is $48 \Omega$. $I_{d i}$, 
$V_{d i}$ and $\gamma_{i}$ represent the measured direct current, DC voltage and extinction angle at the inverter station; also $P$ denotes the active power flowing from the HVDC link. It should be noted that in all of the simulation cases, the equivalent commutating impedance of the inverter has included not only the transformer leakage impedance but also the impedances of filters and the connected AC network [27, 28, 29].

a)
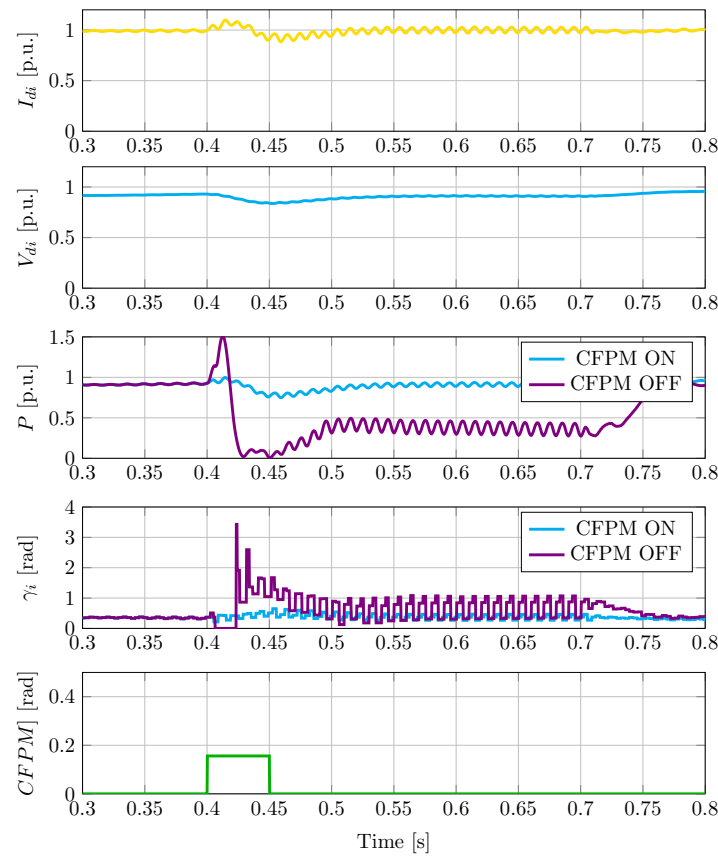

b)
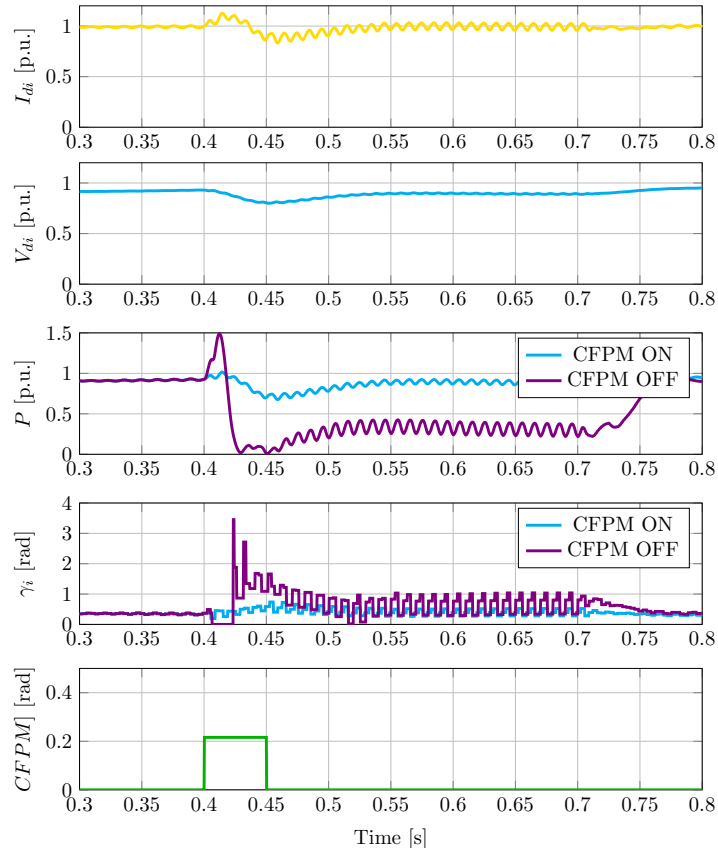

c)
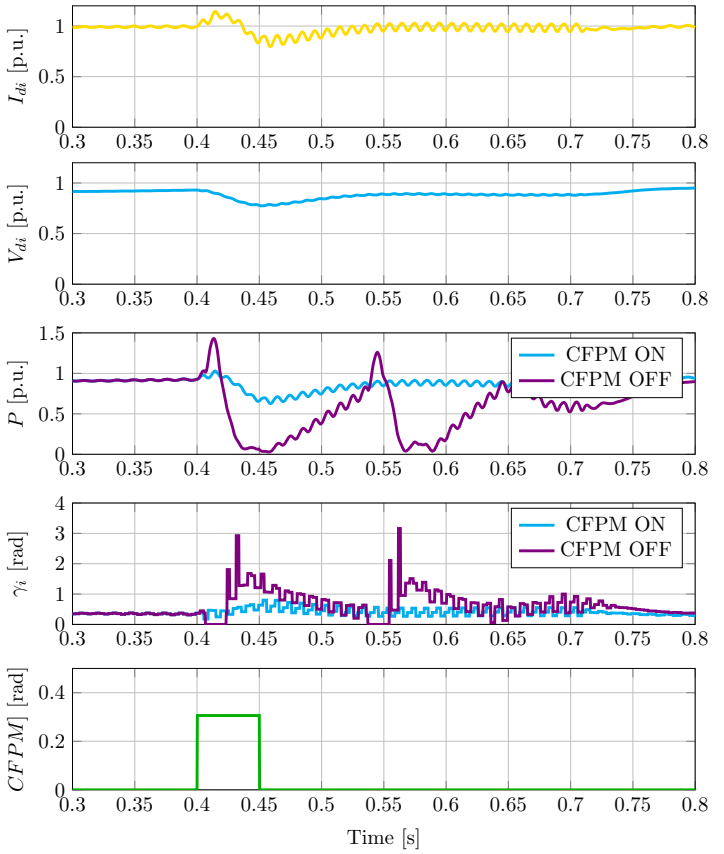

d)
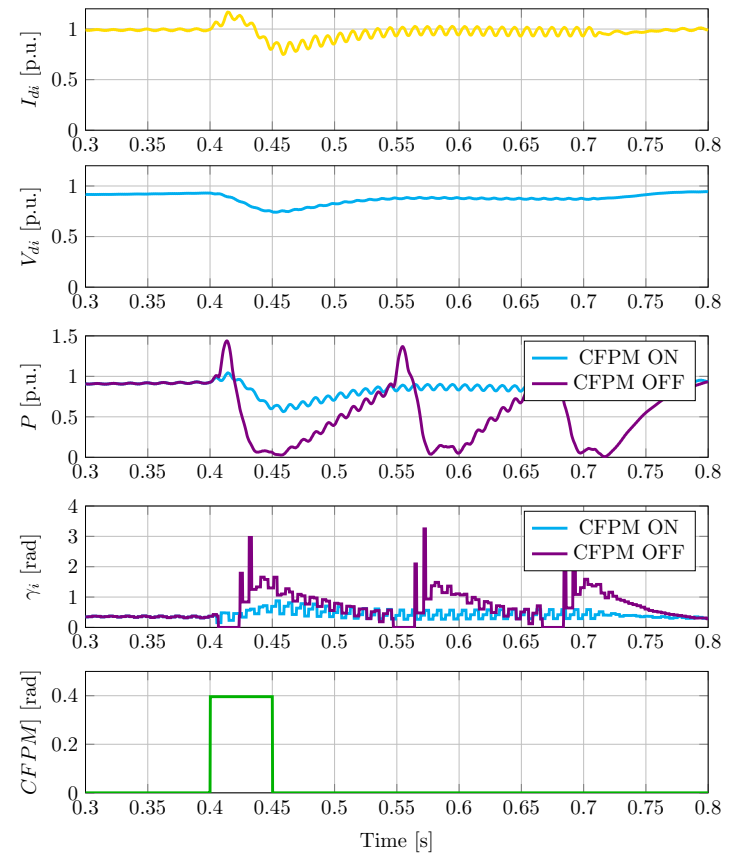

Figure 11: The performance of the proposed control strategy during different types of AC system faults with the fault impedance of $48 \Omega$ at point F in Fig. 10: (a) SLG fault (b) LL fault (c) LLG fault (d) TP fault. 
Referring to Fig. 11(a), when a Single-Line-to-Ground (SLG) fault occurs on phase A at $t=0.4 \mathrm{~s}$, AC voltage decreases and the involved commutating voltages are distorted in phase and reduced in magnitude, which results in reduction of DC voltage $V_{d i}$ magnitude due to principles of AC/DC conversion. This sudden drop in $V_{d i}$, causes $I_{d i}$ to increase to remain the active power $P$ at the rated power of inverter station according to $P=V_{d i} I_{d i}$. Since the overlap angle $(\mu)$ is directly proportional to the direct current, it also increases and reduces the extinction angle $\left(\gamma_{i}\right)$, leading to a commutation failure which interrupts the active power transmission at $t=0.43 \mathrm{~s}$. In order to prevent this event, the CFPM compares the pre- and post-fault Thevenin's impedances seen from the inverter bus, i.e. $Z_{t i b}(t-1)$ and $Z_{t i b}(t)$ in Fig. 12, and applies a pulse depending on the fault intensity about $70 \mu$ s after the fault initiation to decrease the firing angle which leads to increase of $\gamma_{i}$. The applied pulse ends at $t=0.45 \mathrm{~s}, \gamma_{i}$ decreases and VDCOL function in the inverter control system is activated at $t=0.45 \mathrm{~s}$. At this point, $V_{d i}$ reaches the lower setting of VDCOL function to maintain the current order at a constant value. Eventually, the fault is cleared at $t=0.7 \mathrm{~s}$, and the system reaches to its pre-fault values after $0.08 \mathrm{~s}$. The same analysis can be used for Line-to-Line (LL), Line-to-Line-to-Ground (LLG) and Three-Phase (TP) faults as shown in Fig. 11(b), Fig. 11(c) and Fig. 11(d), respectively. It should be noted that $\gamma_{\min }$ (in Fig. 5) has been set such as to consider a lower DC voltage under normal conditions to make the inverter more sensitive to the commutation failure and provide worse conditions for validation of the CFPM performance.

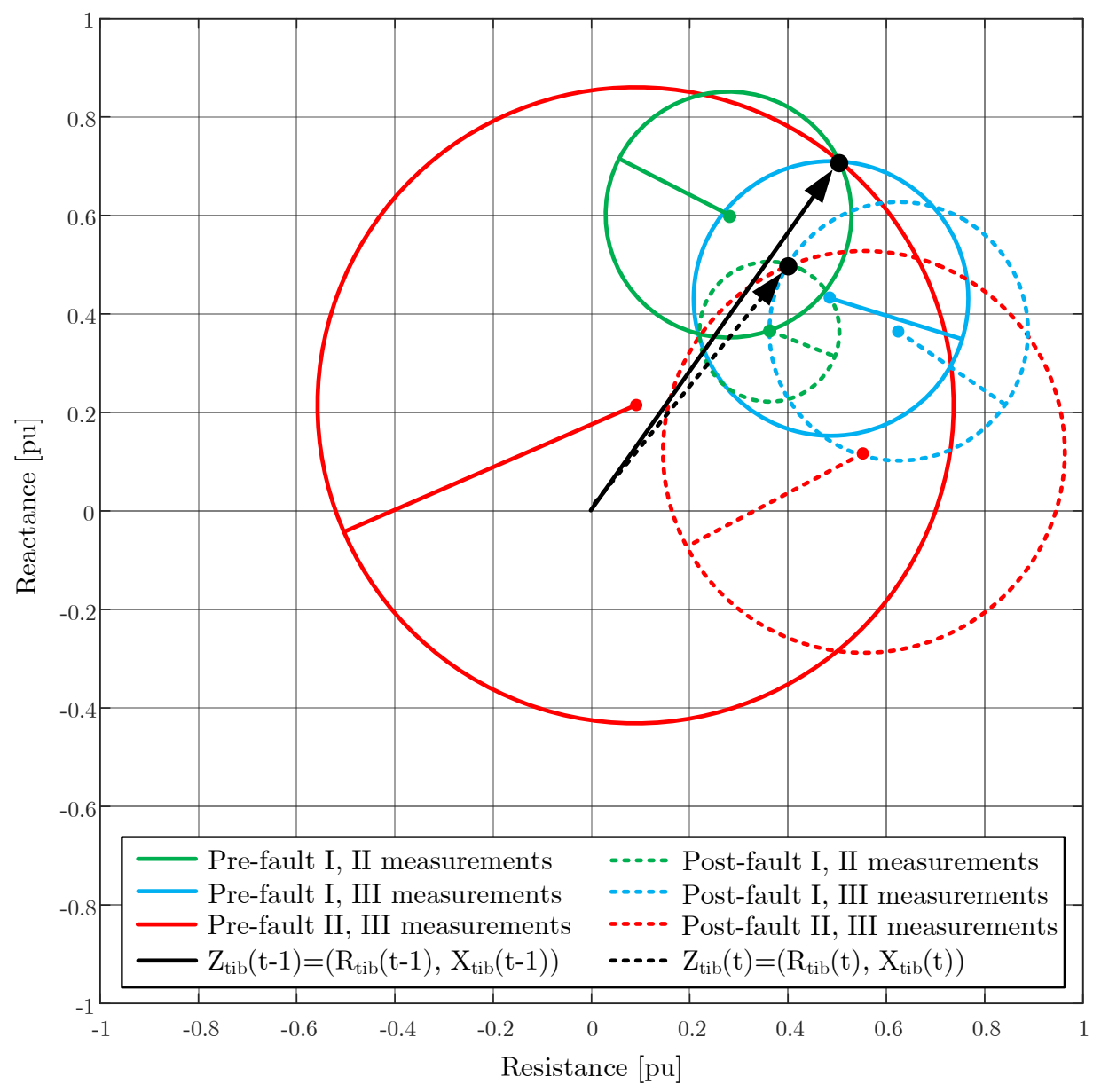

Figure 12: Impedance plane containing the circles obtained from three measurements for determination of pre- and post-fault Thevenin's impedances during SLG fault at point F in Fig. 10. 


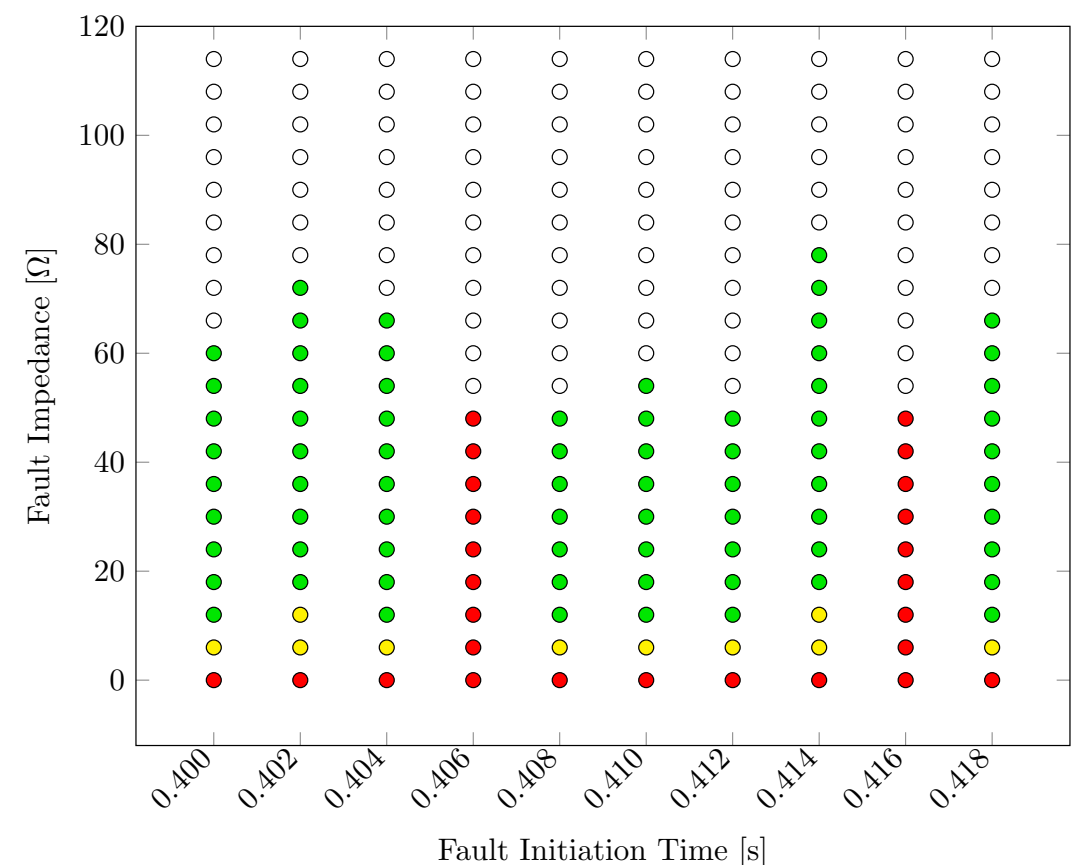

Figure 13: Simulation results for SLG faults under different fault impedances and fault initiation times.

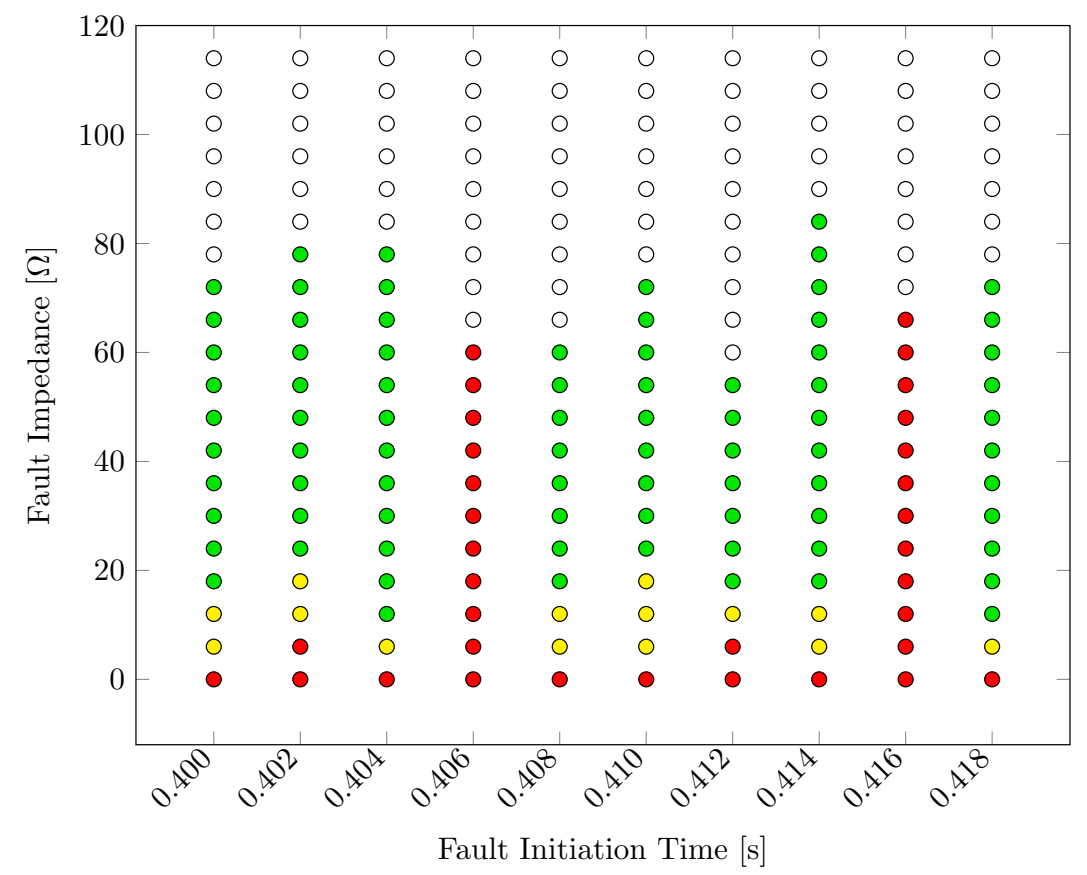

Figure 14: Simulation results for LL faults under different fault impedances and fault initiation times.

Since the nature of AC voltage is sinusoidal, the performance of the proposed control strategy is influenced by the fault initiation time. In order to investigate it, several simulations were conducted, in which faults were applied at different points along the AC voltage sine wave. The simulation results for various types of faults with different fault impedances are shown in Fig. 13 to Fig. 16. In each of the figures, the performance of the proposed control strategy for ten fault initiation times ranged from $0.4 \mathrm{~s}$ to $0.418 \mathrm{~s}$ (covering a complete one cycle) with step times of $0.002 \mathrm{~s}$ are evaluated. Also, the results are reported for different values of fault impedance ranged from $0 \Omega$ to $114 \Omega$. 


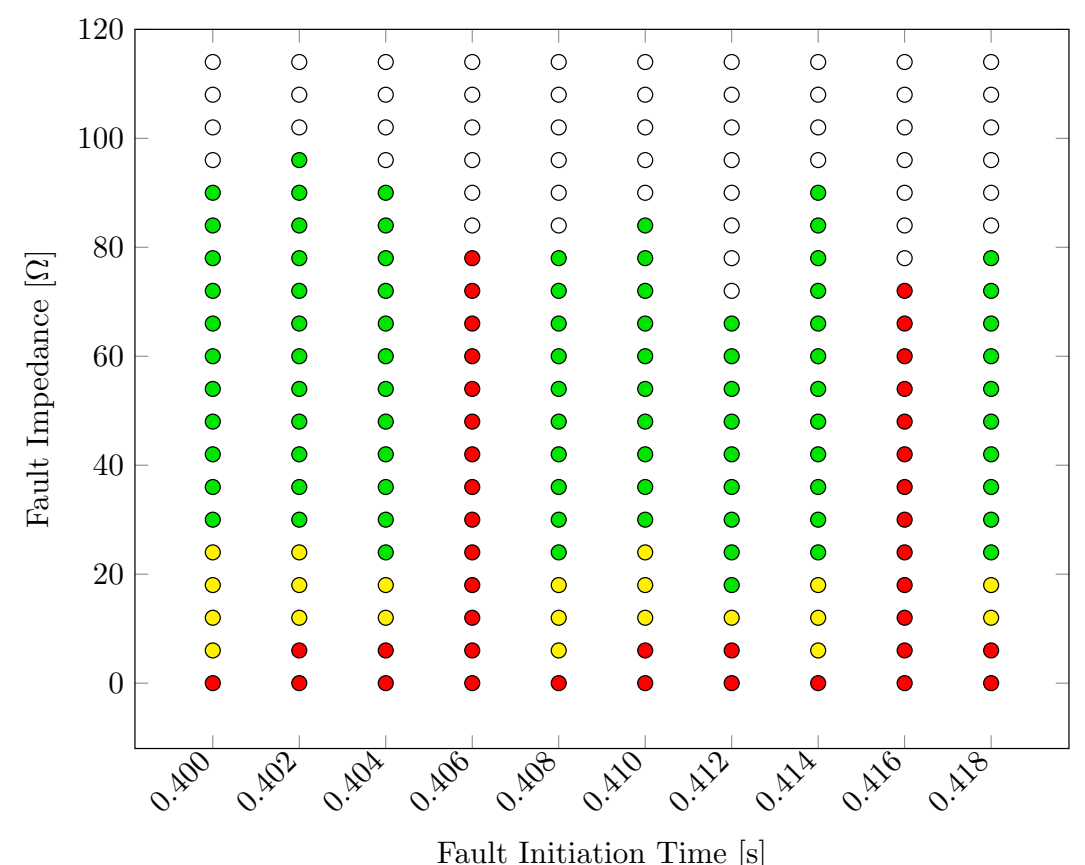

Figure 15: Simulation results for LLG faults with different fault impedances and fault initiation times.

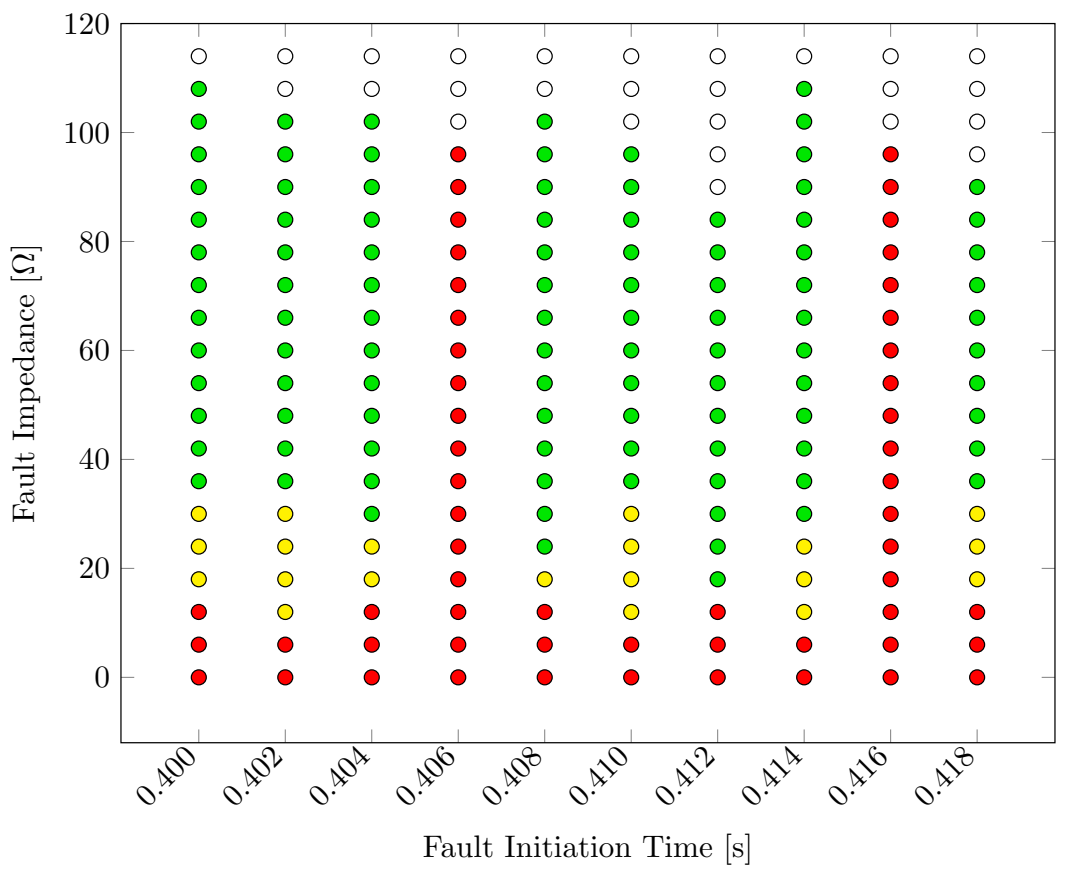

Figure 16: Simulation results for TP faults with different fault impedances and fault initiation times.

In Fig. 13 to Fig. 16, white markers denote the simulation cases, where no failed commutation is observed even without applying the the CFPM. In the majority of fault initiation times with different fault impedances, indicated by green markers, the CFPM can completely prevent commutation failures, whereas in some severer fault conditions which are specified by yellow markers, the decrease of firing angle through the CFPM can only prevent from repetitive commutation failures. Moreover, for some fault initiation times such as $t=0.406 \mathrm{~s}$ and $t=0.416 \mathrm{~s}$, specified by red markers, it cannot be effective at all. It is because of the fact that the commutation process on the involved valves at 
such time instants is going to start immediately, or is ongoing; also, the red cells in other time instants represent the simulation cases, where the fault impedances are too low and the CFPM cannot inhibit the commutation failure. Such a behavior was explained in Subsection 3.2 that values of $\Delta \alpha$ larger than 0.476 rad contrarily cause more commutation failures. Therefore, the proposed CFPM has been designed to prevent commutation failure or repetitive commutation failures with a maximum $\Delta \alpha$ of $0.476 \mathrm{rad}$.

\section{Hardware in the loop testing}

\subsection{Experimental setup}

In order to further validate the performance of the proposed control strategy under real-time conditions, a hardware prototype has been developed. For such a development, the Opal-RT OP5600 HILBOX has been used, integrating digital-analog I/O and GPS cards. More precisely, the system is equipped with an OP5330 analog-out card (16 single-ended digital output channels with a 16-bit resolution D/A converter), an OP5340 analog-in card and a GPS TSync-PCIe card.

The layout of the experimental setup is depicted in Fig. 17. The entire real-time model consists of two separate subsystems, whereby 'Subsystem A' represents the power network (i.e. LCC-HVDC system), and 'Subsystem B' represents the control system including the proposed CFPM. The input signals to the control system (Subsystem B) are extinction angles, and DC and AC voltages and currents produced by Subsystem A (i.e. measurements at the inverter side). Accordingly, the output of the control system (which is the determined firing angle for the inverter thyristors) forms an input to Subsystem A. The signals' exchange between these two subsystems is done through actual electrical connections between analog-in and analog-out cards. The electrical connections are established using DB-37 breakout slim boards. Also, in order to get time-synchronized measurements (i.e. realization of PMU) TSync-PCIe GPS card is applied.

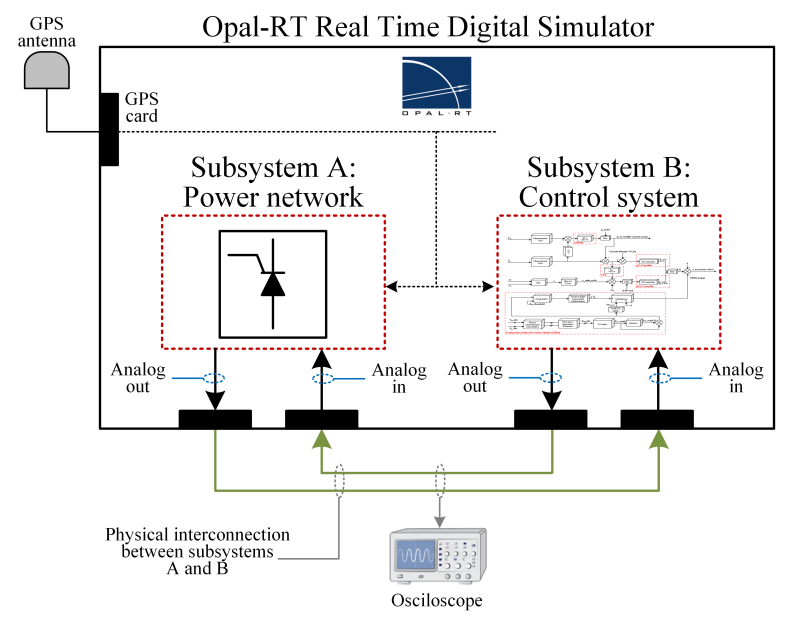

Figure 17: Experimental setup.

It should be noted that all of the input and output signals are converted to proportional voltages. Moreover, the signals have been scaled up by a factor of three (compared to the results shown in Fig. 11). The actual experimental arrangement is depicted in Fig. 18. 


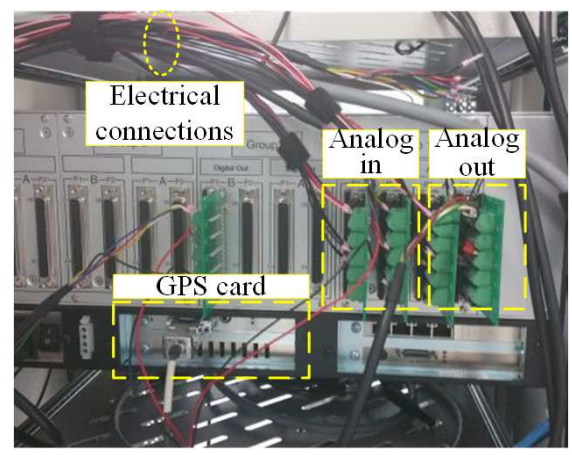

a)

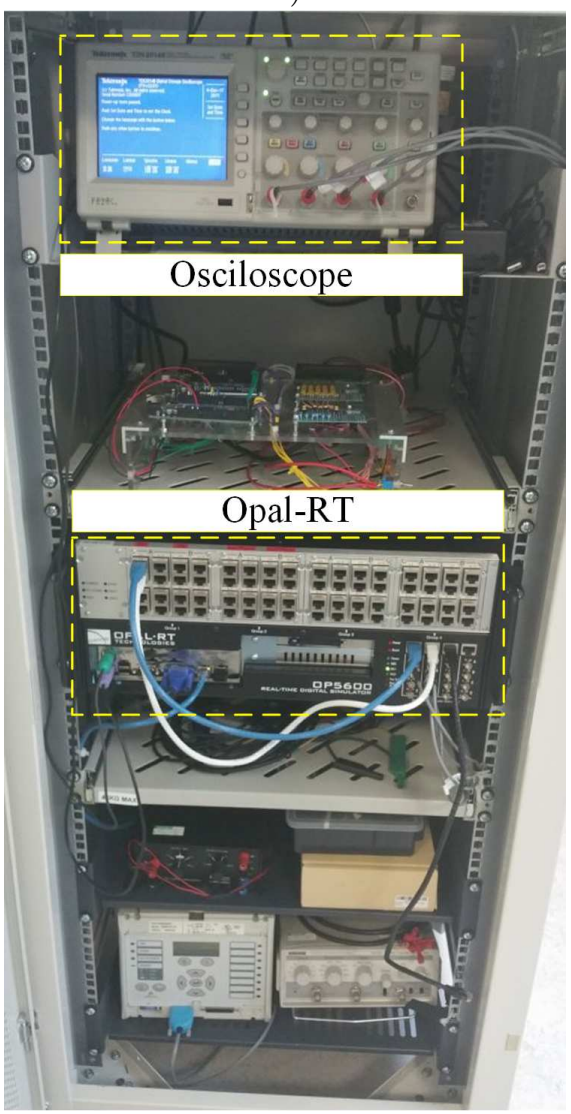

b)

Figure 18: Experimental arrangement: a) Opal-RT rear part b) Opal-RT front part.

\subsection{Experimental results}

The experimental results captured during real-time simulation are presented in Fig. 19. For ease of comparison between simulation- and experiment-based performance of the proposed scheme, the four study cases presented in Section 4.2 (Fig. 11). As can be seen from the figure, the results obtained from the experiments match the simulation results shown in Fig. 11, and the proposed approach can effectively prevent the commutation failure or repetitive commutation failures during different types of AC faults. 


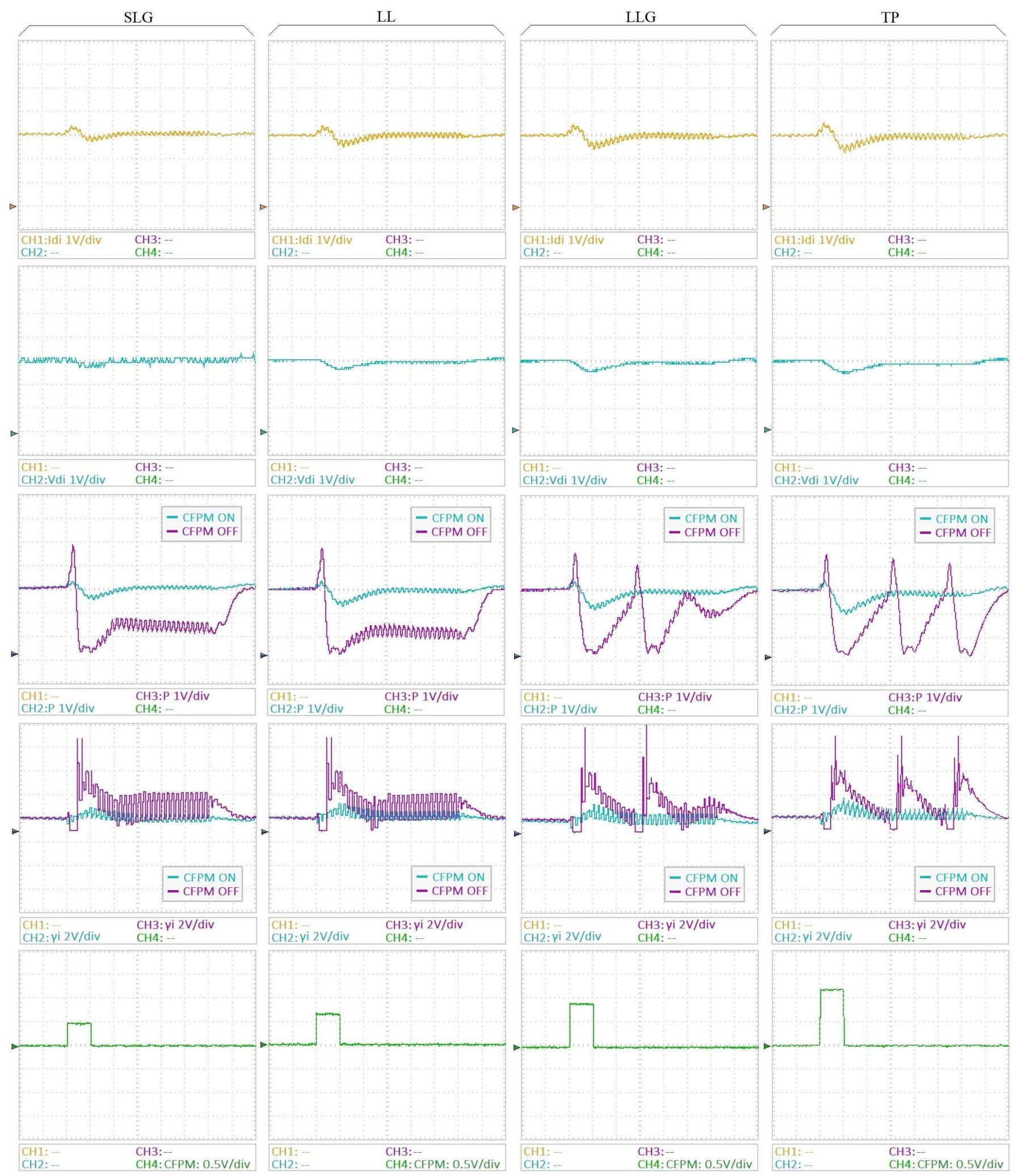

Figure 19: Experimental results of the proposed strategy under different types of AC faults.

\section{Conclusions}

One of the main drawbacks of the existing firing angle-based control strategies in LCC-based HVDC systems is that the intensity of fault incident is neglected in determination of the firing angle deduction. In this paper, after 
further investigation of communication failure mechanism, a predictive control strategy was proposed, in which the difference between pre- and post- fault values of Thevenin's impedance seen from the inverter AC bus was utilized for determination of fault severity and deduction of the firing angle. To verify the feasibility of the proposed approach, SLG, LL, LLG, and TP faults with diverse fault impedances and fault initiation times were applied to an LCC-HVDC test network. The simulation and experimental results indicated that the proposed approach is able to considerably prevent the commutation failure or repetitive commutation failures during different types of AC faults.

\section{Acknowledgement}

The present article outlines the result of a collaborative work conducted between Tsinghua University, Beijing, People's Republic of China, Strathclyde University, Glasgow, United Kingdom, and Universiti Teknologi Malaysia, Johor, Malaysia. This work is supported in part by the National Natural Science Foundation of China (Grant No. 51120175001), in part by the National Key Research and Development Plan of China (Grant No. 2016YFB0900600), and in part by Royal Society of Edinburgh (J. M. Lessells Scholarship).

\section{References}

[1] J. Wu, H. Li, G. Wang, Y. Liang, An improved traveling-wave protection scheme for LCC-HVDC transmission lines, IEEE Transactions on Power Delivery 32 (1) (2017) 106-116.

[2] H. Xiao, Y. Li, R. Liu, X. Duan, Single-end time-domain transient electrical signals based protection principle and its efficient setting calculation method for LCC-HVDC lines, IET Generation, Transmission Distribution 11 (5) (2017) 1233-1242.

[3] Y. Xue, X. P. Zhang, Reactive power and ac voltage control of LCC HVDC system with controllable capacitors, IEEE Transactions on Power Systems 32 (1) (2017) 753-764.

[4] C. Guo, Y. Zhang, A. M. Gole, C. Zhao, Analysis of dual-infeed HVDC with LCC HVDC and VSC HVDC, IEEE Transactions on Power Delivery 27 (3) (2012) 1529-1537.

[5] C. V. Thio, J. B. Davies, K. L. Kent, Commutation failures in HVDC transmission systems, IEEE Transactions on Power Delivery 11 (2) (1996) 946-957.

[6] J. Zhu, Y. Li, X. Duan, Application of SFCLs to inhibit commutation failure in HVDC systems: Position comparison and resistance recommendation, Canadian Journal of Electrical and Computer Engineering 40 (1) (2017) 31-40.

[7] X. Zhou, Simultaneous commutation failures and forced blocking of multi-in-feed HVDC in east china power grid, in: CIGRE Large Disturbances Workshop, 2014, pp. 21-32.

[8] L. Liu, The study of fuzzy controller in MTDC system, Power System Technology (Chinese) 22 (9) (1998) 22-26. 
[9] T. Machida, Y. Yoshida, A method to detect the deionization margin angle and to prevent the commutation failure of an inverter for DC transmission, IEEE Transactions on Power Apparatus and Systems PAS-86 (3) (1967) 259-262.

[10] K. Vijay, HVDC and FACTs controllers: Applications of static converters in power systems, Kluwer Academic Publishers - Boston, 2004.

[11] S. Tamai, H. Naitoh, F. Ishiguro, M. Sato, K. Yamaji, N. Honjo, Fast and predictive HVDC extinction angle control, IEEE Transactions on Power Systems 12 (3) (1997) 1268-1275.

[12] J. V. Wijayakulasooriya, G. A. Putrus, C. H. Ng, Fast non-recursive extraction of individual harmonics using artificial neural networks, IEE Proceedings - Generation, Transmission and Distribution 152 (4) (2005) 539-543. doi:10.1049/ip-gtd:20045089.

[13] A. Hansen, H. Havemann, Decreasing the commutation failure frequency in HVDC transmission systems, IEEE Transactions on Power Delivery 15 (3) (2000) 1022-1026.

[14] L. Zhang, L. Dofnas, A novel method to mitigate commutation failures in HVDC systems, in: International Conference on Power System Technology, Vol. 1, 2002, pp. 51-56 vol.1.

[15] Z. Wei, Y. Yuan, X. Lei, H. Wang, G. Sun, Y. Sun, Direct-current predictive control strategy for inhibiting commutation failure in HVDC converter, IEEE Transactions on Power Systems 29 (5) (2014) 2409-2417.

[16] C. Guo, C. Li, C. Zhao, X. Ni, K. Zha, W. Xu, An evolutional line-commutated converter integrated with thyristor-based full-bridge module to mitigate the commutation failure, IEEE Transactions on Power Electronics 32 (2) (2017) 967-976.

[17] Z. Liu, J. Yu, X. Guo, T. Sun, J. Zhang, Survey of technologies of line commutated converter based high voltage direct current transmission in china, CSEE Journal of Power and Energy Systems 1 (2) (2015) 1-8.

[18] J. G. Mayordomo, . Carbonero, L. F. Beites, R. Asensi, W. Xu, A contribution towards a general and systematic procedure for modeling line commutated AC/DC converters in the harmonic domain, IEEE Transactions on Power Delivery 24 (4) (2009) 2415-2427.

[19] I. Oketch, Improvement in algorithm for commutation failure prevention in LCC HVDC, Master's thesis, University of Technology, Gothenburg, Sweden (2016).

[20] O. E. Oni, I. E. Davidson, K. N. I. Mbangula, A review of LCC-HVDC and VSC-HVDC technologies and applications, in: IEEE 16th International Conference on Environment and Electrical Engineering (EEEIC), 2016, pp. 1-7.

[21] Z. Wei, J. Liu, W. Fang, J. Hou, Z. Xiang, Commutation failure analysis in single- and multi-infeed HVDC systems, in: IEEE PES Asia-Pacific Power and Energy Engineering Conference(APPEEC), 2016, pp. 2244-2249.

[22] C. D. Barker, R. S. Whitehouse, R. Gupta, M. Li, Static characteristics of LCC converters in a multi-terminal configuration, in: 13th IET International Conference on AC and DC Power Transmission, 2017, pp. 1-5. 
[23] M. Khajeh, Protection of hybrid AC/DC grids based on thevenins theorem, Phd thesis, Faculty of Electrical Engineering, University Teknologi Malaysia (UTM) (2016).

[24] M. R. Miveh, M. Gandomkar, S. Mirsaeidi, M. R. Gharibdoost, A review on protection challenges in microgrids, in: 2012 Proceedings of 17th Conference on Electrical Power Distribution, 2012, pp. 1-5.

[25] B. Alinejad, H. K. Karegar, On-line thevenin impedance estimation based on PMU data and phase drift correction, IEEE Transactions on Smart Grid PP (99) (2016) 1-1. doi:10.1109/TSG.2016.2574765.

[26] M. O. Faruque, Y. Zhang, V. Dinavahi, Detailed modeling of CIGRE HVDC benchmark system using PSCAD/EMTDC and PSB/SIMULINK, IEEE Transactions on Power Delivery 21 (1) (2006) 378-387.

[27] Y. Li, F. Liu, L. Luo, C. Rehtanz, Y. Cao, Enhancement of commutation reliability of an HVDC inverter by means of an inductive filtering method, IEEE Transactions on Power Electronics 28 (11) (2013) 4917-4929.

[28] Y. Li, L. Luo, C. Rehtanz, S. Rberg, F. Liu, Realization of reactive power compensation near the LCC-HVDC converter bridges by means of an inductive filtering method, IEEE Transactions on Power Electronics 27 (9) (2012) 3908-3923.

[29] Y. Li, L. Luo, C. Rehtanz, D. Yang, S. Rberg, F. Liu, Harmonic transfer characteristics of a new HVDC system based on an inductive filtering method, IEEE Transactions on Power Electronics 27 (5) (2012) 2273-2283.

\section{Biographies}

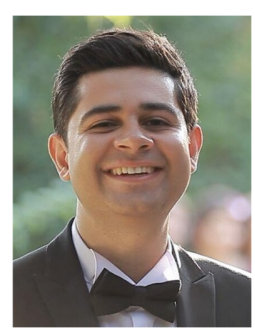

Sohrab Mirsaeidi (M'17) received his Ph.D. degree in Electrical Engineering from Universiti Teknologi Malaysia (UTM), Johor, Malaysia in 2016. Currently, he is a Postdoctoral Fellow with the Department of Electrical Engineering, Tsinghua University, Beijing, China. Dr. Mirsaeidi has published more than 40 scientific papers and books in the field of control and protection of power systems. He has also been involved in several key research projects funded by the Chinese government. His main research interests include control and protection of large hybrid AC/DC grids, distributed generation, and microgrids.

Xinzhou Dong (M'99 - SM'01 - F'16) was born in Shaanxi, China, in 1963. He received the

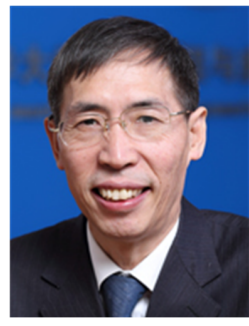
B.Sc., M.Sc., and Ph.D. degrees in Electrical Engineering from Xi'an Jiaotong University, China, in 1983, 1991, and 1996, respectively. He furthered his postdoctoral research at the Electrical Engineering Station of Tianjin University, Tianjin, China, from 1997 to 1998. Since 1999, he has been employed by Tsinghua University, Beijing, China. Currently, he is a Professor with Dept. of Electrical Engineering, Tsinghua University and Director of the International Union Research Center of Beijing on Green Energy and Power Safety. His research interests include protective relaying, fault location, and the application of wavelet transforms in power systems. Prof. Dong is a Fellow of IEEE and IET. He is an author or co-author of more than 200 journal papers. 


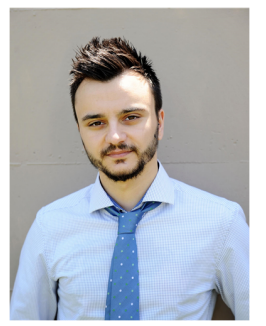

Dimitrios Tzelepis (S'13 - M'17) received the B.Eng in Electrical Engineering, the M.Sc in Wind Energy Systems, and Ph.D in Protection, Fault Location and Control in MTDC grids from Technological Education Institution of Athens (2013) and University of Strathclyde (2014) and (2017) respectively. He is currently a Post-Doctoral Researcher with Department of Electronic and Electrical Engineering, University of Strathclyde, Glasgow, U.K. His main research interests include power systems protection, relay algorithms, application of advanced signal analysis in protection and fault location applications and HVDC protection, fault location and control.

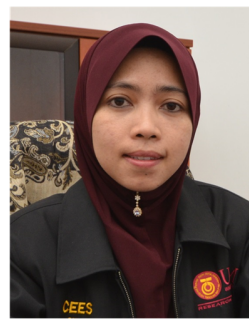

Dalila Mat Said (M'13) is a Senior Lecturer at Centre of Electrical Energy Systems, Faculty of Electrical Engineering, Universiti Teknologi Malaysia (UTM). She has 12 years of experience in teaching electrical engineering courses and supervision of more than 30 undergraduates, and 20 post graduates students. She has an experience within the area of power quality consultancy. She was involved in the Power Quality Baseline Study in a Peninsular Malaysia (2010-2013) under the Energy Commission of Malaysia. She is a member of IEM, IET and IEEE.

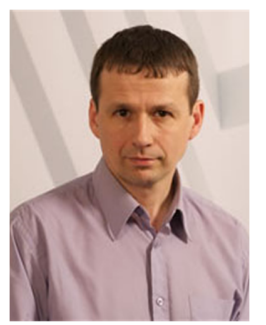

Adam Dyśko (M'06) received the Ph.D. degree in Electrical and Electronic engineering from the University of Strathclyde, Glasgow, U.K., in 1998. He is currently a Senior Lecturer with the Department of Electronic and Electrical Engineering. $\mathrm{He}$ teaches a variety of Electrical Engineering subjects and has been leading a number of research projects with both academic and industrial partners. His research interests include power system protection, system control and stability, and power quality.

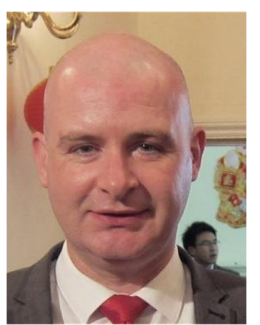

Campbell Booth received the B.Eng. and Ph.D. degrees in electrical and electronic engineering from the University of Strathclyde, Glasgow, UK in 1991 and 1996, respectively. He is currently a Professor and Head of Department for Electronic and Electrical Engineering, University of Strathclyde. His research interests include power system protection; plant condition monitoring and intelligent asset management; applications of intelligent system techniques to power system monitoring, protection, and control; knowledge management; and decision support systems. 